\title{
Harmonic Research in Direct AC - AC Variable Frequency Power Converter
}

\author{
Kavitha, R Premalatha, K., Rajalakshmi, D.
}

\begin{abstract}
Direct AC-AC converter circuit termed as cyclo-converter converts fixed AC voltage, fixed frequency into variable $A C$ voltage, variable frequency without using intermediate DC link. Cyclo-converter generates considerable harmonics when operated at variable frequency and load. The impact of harmonics is studied at multiples of lower order frequencies and firing angle. Simulation studies are performed and harmonic spectrum, Total Harmonic Distortion (THD) are diagnosed by employing MATLAB/SIMULINK platform. The Hardware prototype is implemented and the voltage waveform, harmonic profile is analyzed in real time using power logger.
\end{abstract}

Keywords-Cyclo-converter, Harmonic spectrum, THD

\section{INTRODUCTION}

AC-AC frequency conversion plays a vital role in wind energy conversion system, mining industry, ship propulsion drives and in grinding mill drives [1-2]. AC-AC conversion plays significant role in rolling mills as the main requirement of the converter is precise control at frequencies lower than the input frequency [3-5].The effects of different control techniques on the input harmonics is analyzed in [6]. The simulation results of harmonics present in cycloconverter for various frequencies is presented in [7].Time results in the benefits of detectingabnormalities and fault detection [8]. Harmonic spectral components vary based on amplitude and output frequency in a cyclo-converter drive. Inter harmonics that are present near the fundamental frequency increases to about $40 \%$ of the fundamental when cyclo-converter drive is operated and it leads to high power losses in transformer [9-11].In direct AC-AC Power conversion systems, STATCOMs (static compensators), Active Filters and Hybrid Filters are employed to compensate the effect of the harmonics and inter harmonics produced in cyclo-converter [12-14].

$\mathrm{AC}-\mathrm{AC}$ frequency conversion is achieved by i) DC link converter (Rectifier -Inverter) and Direct frequency converters (cyclo-converter). The merits of cyclo-converter over DC link converter is it does not utilize energy storage component like dc capacitor or a dc reactor and the power transmission between input and output terminals is direct. Harmonics and THD are important concern in most direct $\mathrm{AC}$ to $\mathrm{AC}$ frequency changers. The harmonics that are generated in direct $\mathrm{AC}$ to $\mathrm{AC}$ frequency changers causes

Revised Manuscript Received on August 19, 2019.

Kavitha, Associate Professor, Electrical and Electronics Engineering, Kumaraguru College of Technology, Coimbatore, TamilNadu, India. (E-mail: kavitha.r.eee@kct.ac.in)

R Premalatha, Associate Professor, Electrical and Electronics Engineering, Kumaraguru College of Technology, Coimbatore, TamilNadu, India.(E-mail: premalatha.k.eee@kct.ac.in)

K., Rajalakshmi, D, Associate Professor, Electrical and Electronics Engineering, Kumaraguru College of Technology, Coimbatore, TamilNadu, India.(E-mail: rajalakshmi.d.eee@kct.ac.in) domain analysis and frequency analysisof cyclo-converter

over-heating and reduces the efficiency of the system. The objective of the research is to analyze the harmonics in direct ac - ac converters by using MATLAB Simulink. To implement the cyclo-converter and analyze the frequency spectrum in hardware.

\section{METHODOLOGY}

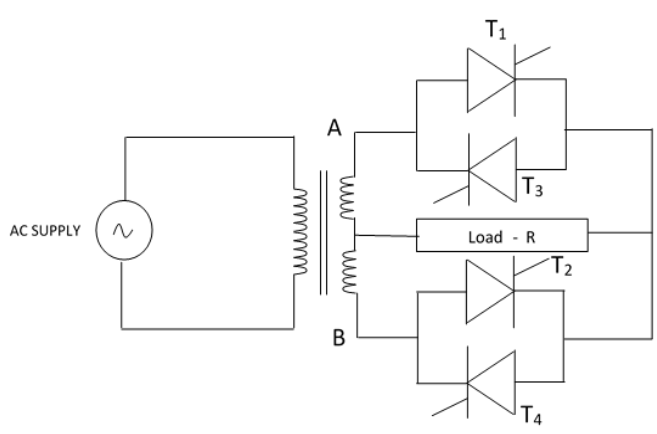

Fig.1. Circuit diagram of AC-AC converter

The power circuit of Direct AC to AC frequency converter is shown in figure.1.The circuit consists of positive group of Thyristor (T1 and $\mathrm{T} 2$ ) and negative group of Thyristor (T3 and T4). The SCR T1 is turned on during positive half cycle and the load current flows through A Thyristor T1 - R - midpoint of transformer. Thyristor T1 automatically turned off during negative cycle. During negative half cycle thyristors $\mathrm{T} 2$ is turned on and current flows through B- Thyristor T2 -R- midpoint of transformer. During both the positive and negative half cycle current flows to the load in the same positive direction and thus termed as positive group of thyristor.

The SCR T3 is turned on during negative half cycle and the load current flows through midpoint of transformer - $\mathrm{R}$ ThyristorT3-A.During positivehalf cycle thyristors T4is turned on and current flows through midpoint of transformer -R- ThyristorT3-A .During both the positive and negative half cycle current flows to the load in the same negative direction and thus termed as negative group of thyristor [15].

\section{SIMULATION RESULTS}

The cyclo-converter is simulated in MATLAB-SIMULINK for various frequencies. The input waveform is presented in fig.2 a). The simulated output waveforms and harmonic spectrum for frequencies of $25 \mathrm{~Hz}, 16.66 \mathrm{~Hz}$ and $12.5 \mathrm{~Hz}$ are presented in Fig.2(b)-2(d) respectively. It is observed that 
the even order harmonics are absent owing to the half wave symmetry of the output waveform. Further the THD is increased with reduction in output frequency and the lower order harmonics are more pronounced.
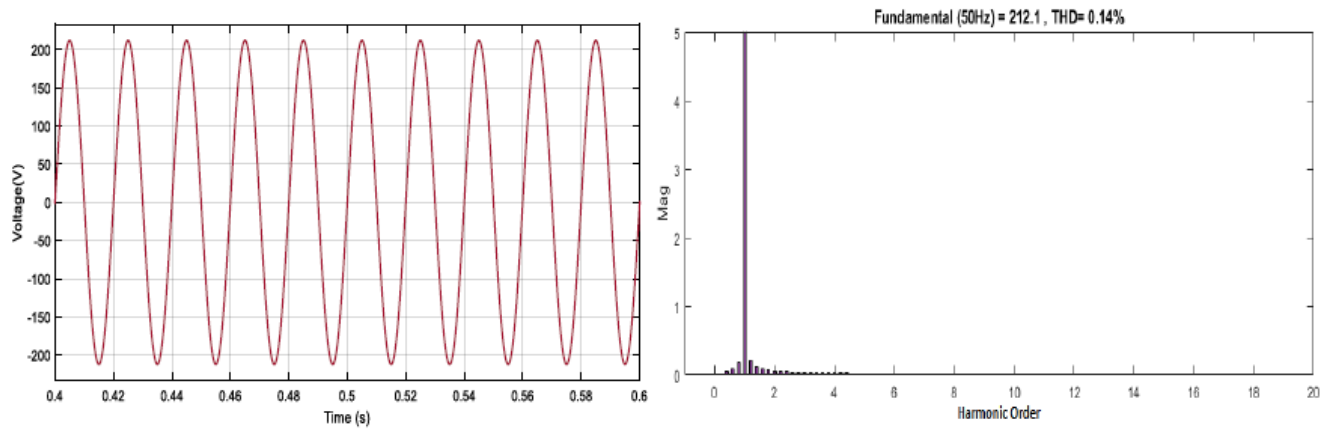

(a)

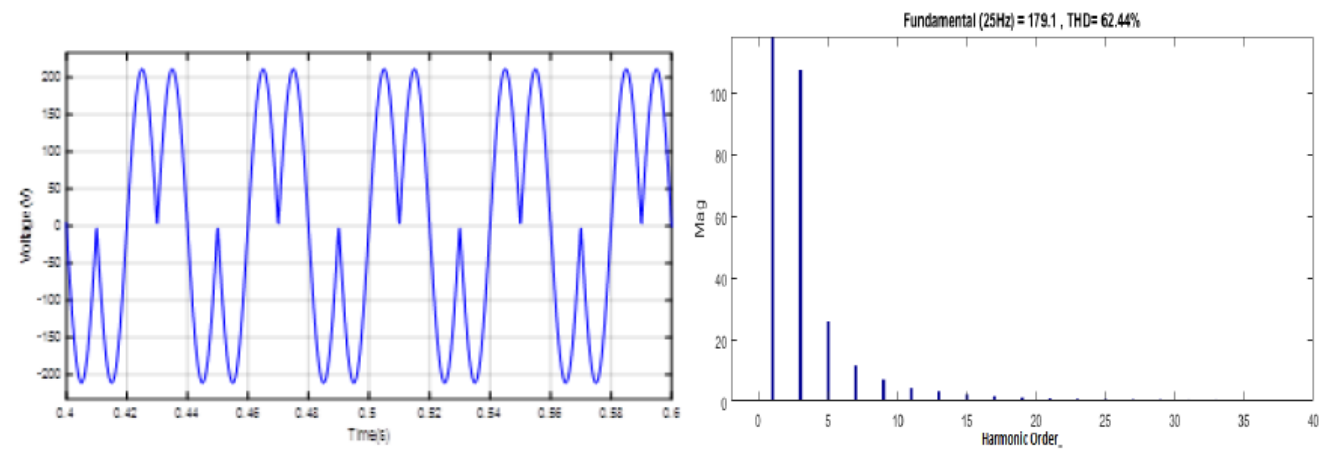

(b)
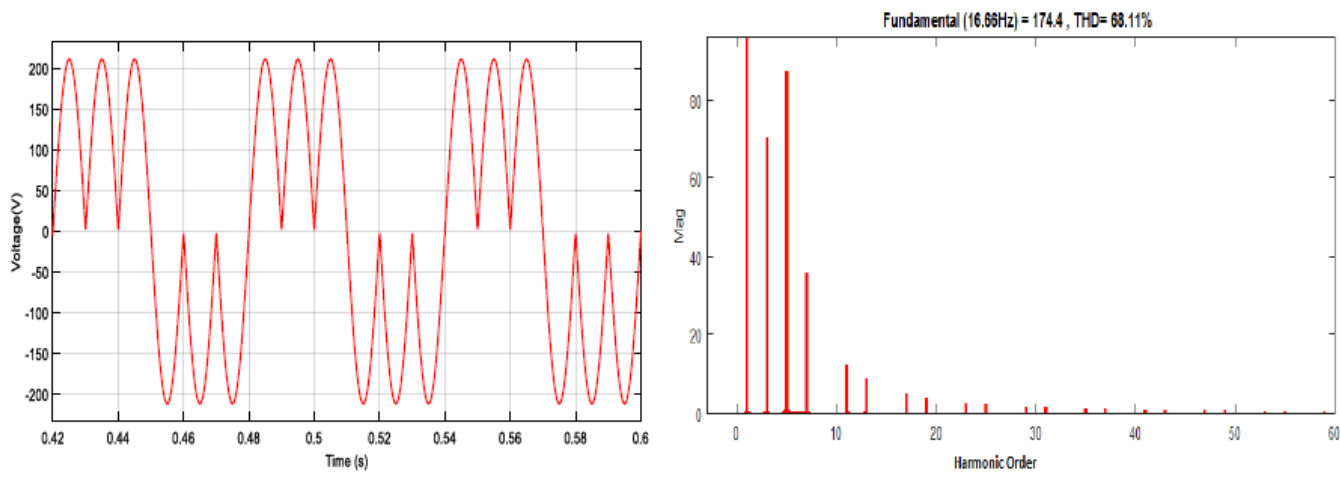

(c)
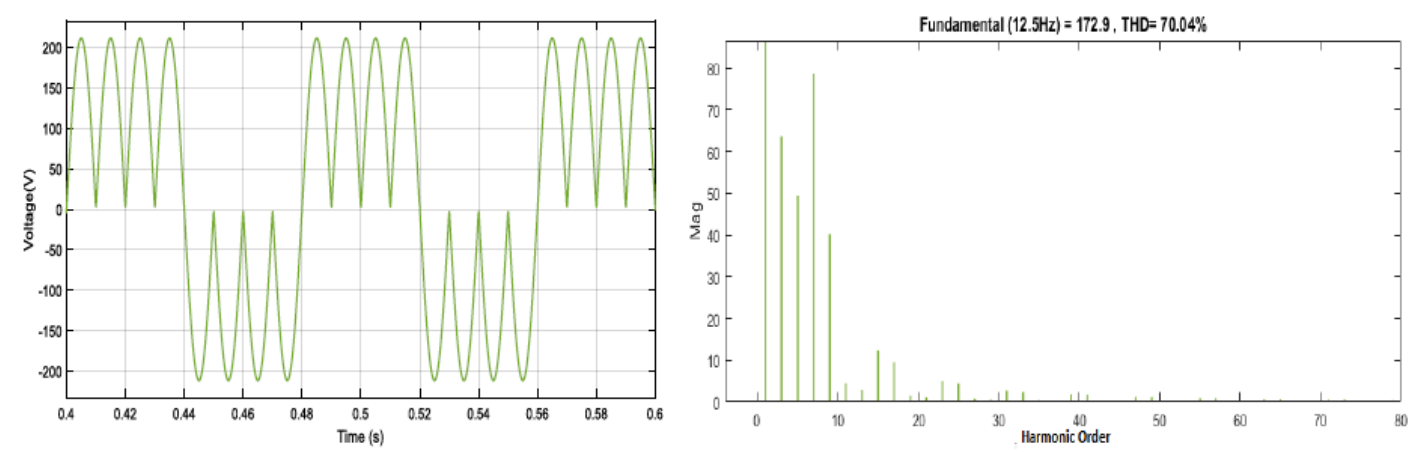

(d)

Fig. .Simulation results of Voltage waveform and Harmonic Spectrum: (a) input at 50Hz frequency (b) output at

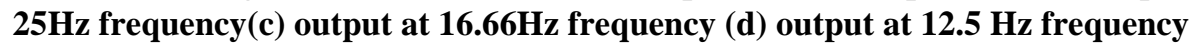




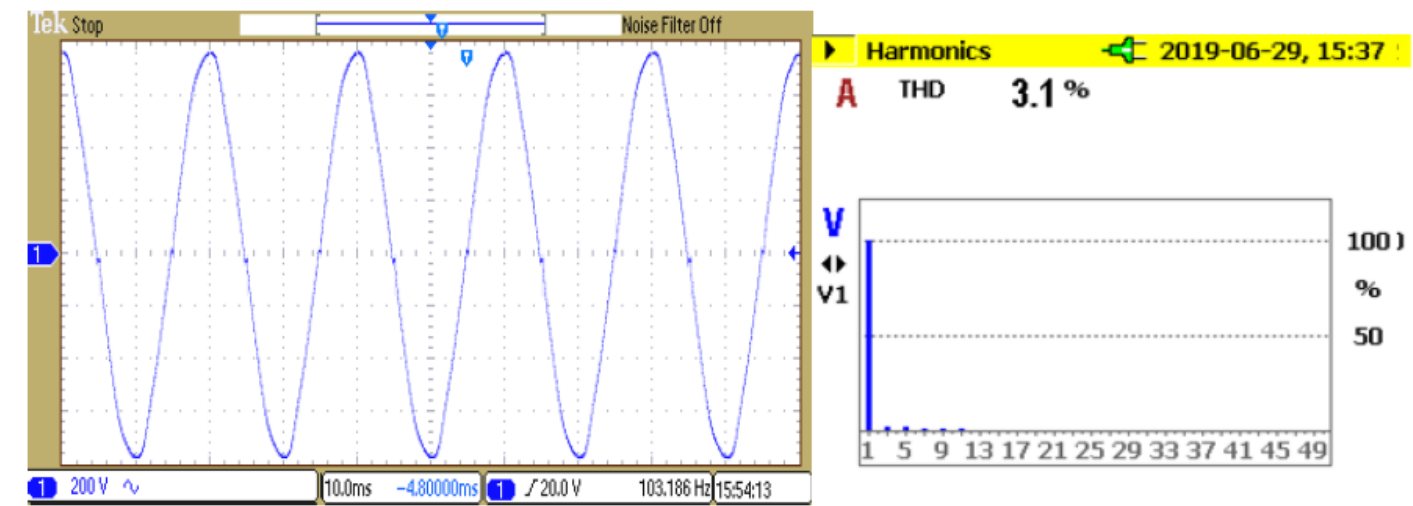

(a)

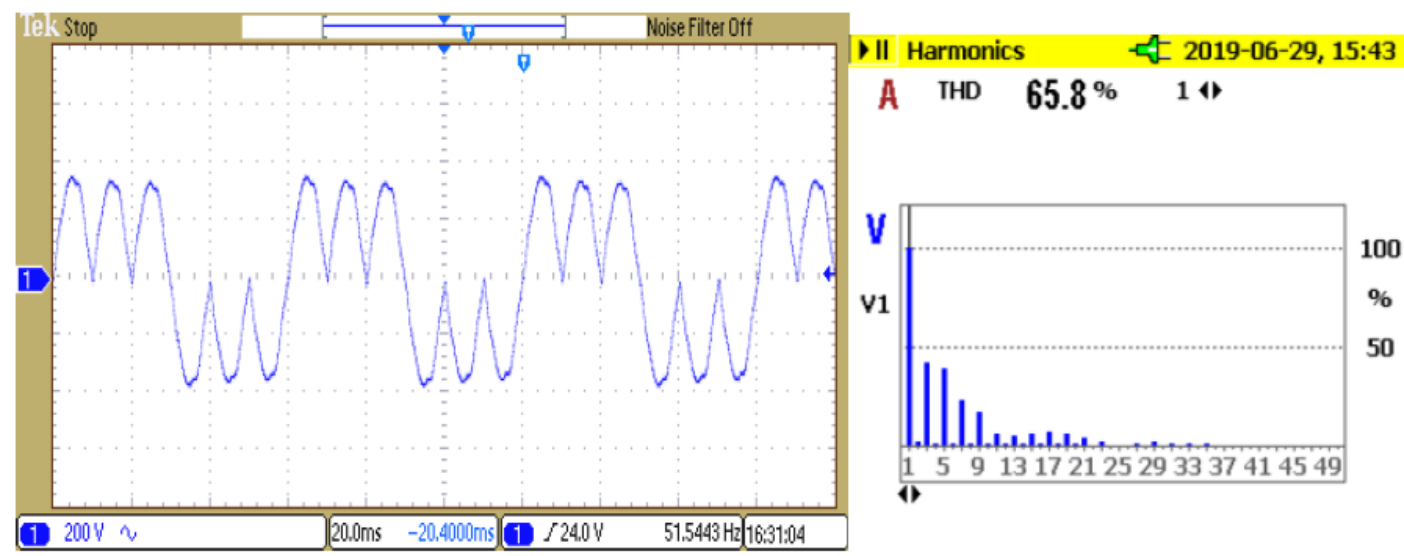

(b)

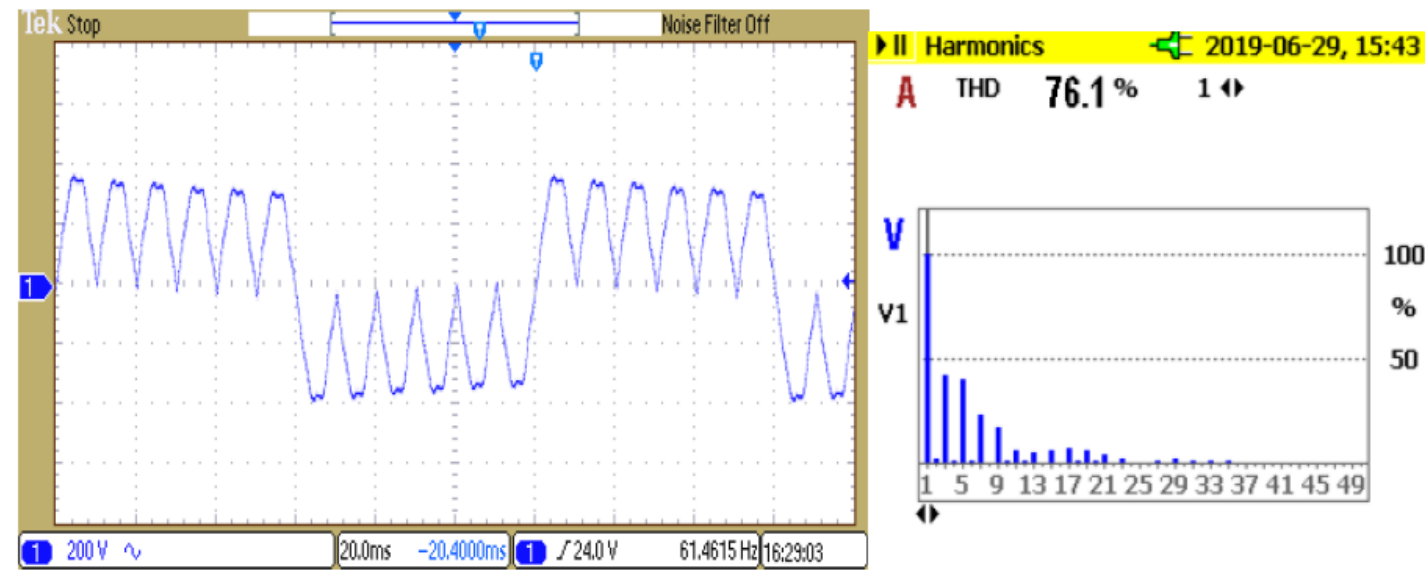

(c)

Fig.3 .Hardware results of Voltage waveform andHarmonic Spectrum:(a) input at 50Hz frequency (b)output at 16.66Hz frequency (c) output at $8.33 \mathrm{~Hz}$ frequency

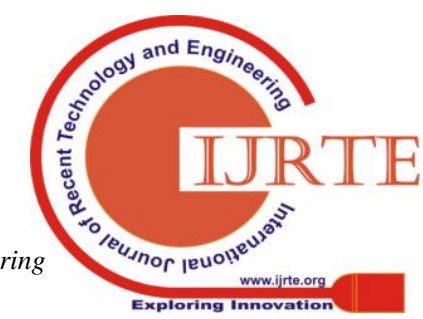




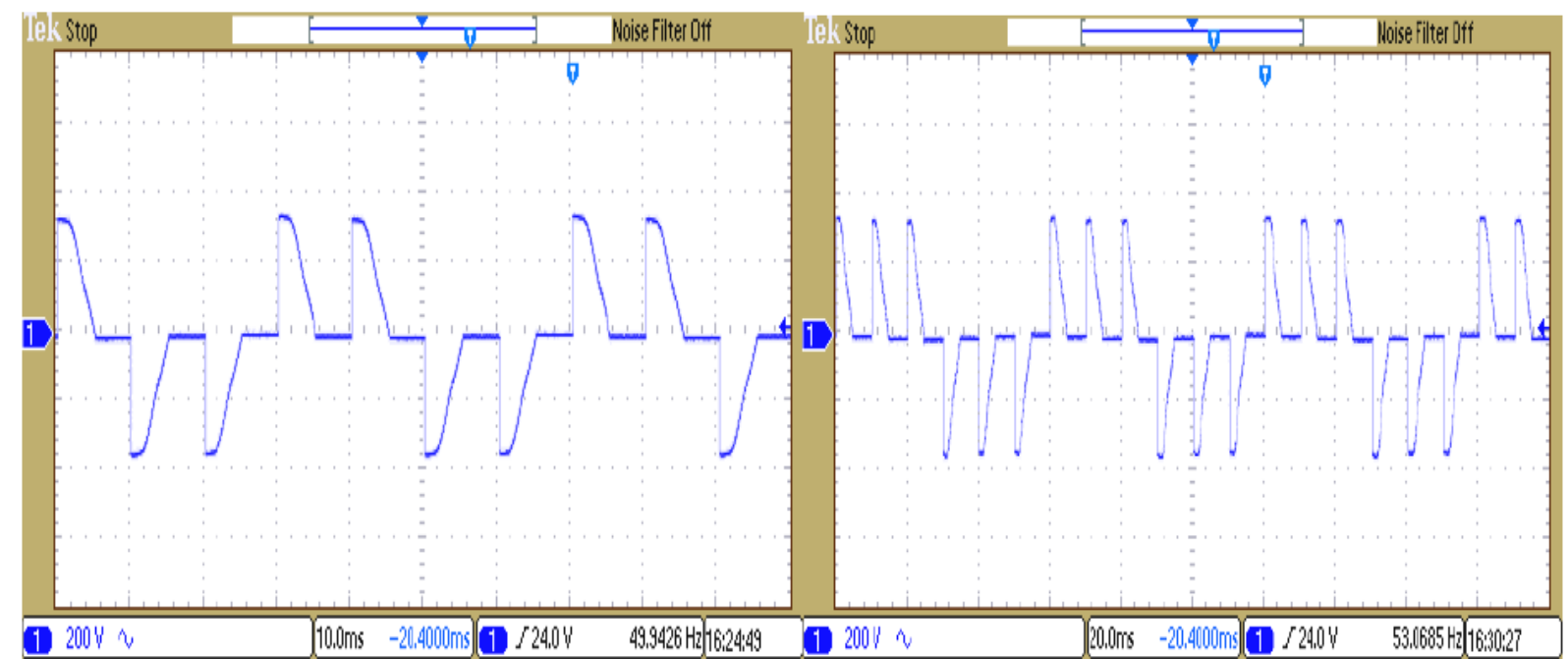

(a)

(b)

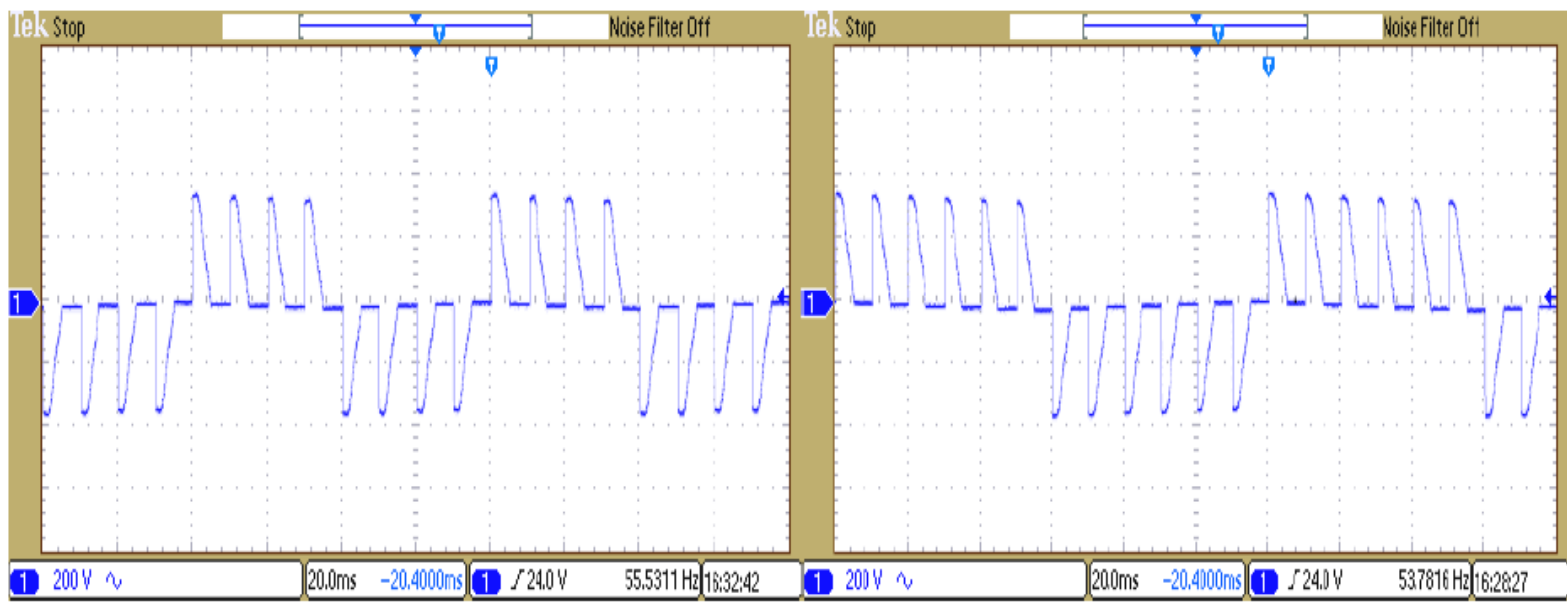

(c)

(d)

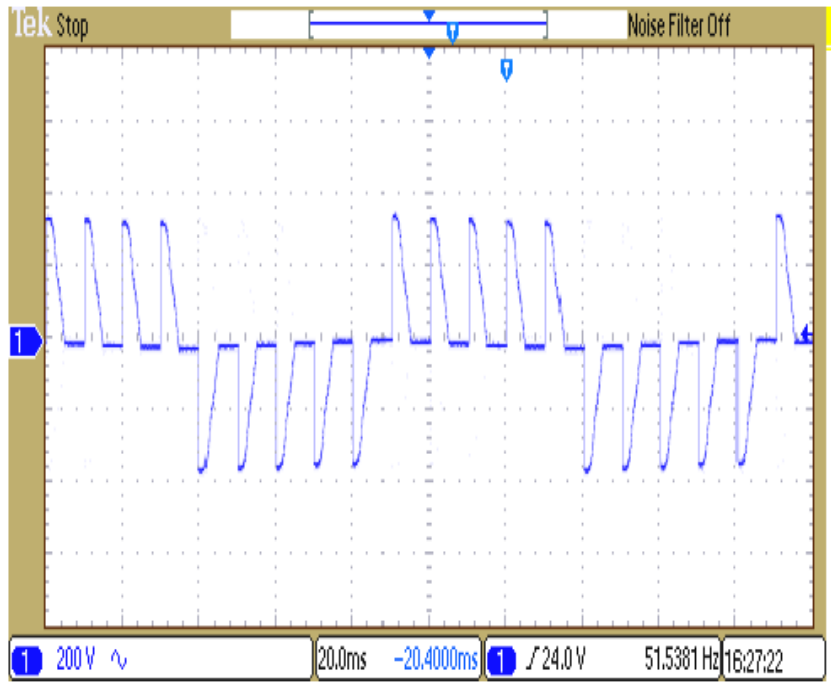

(e)

\section{- II Harmonics \\ A THD $98.9 \% \quad 14$}

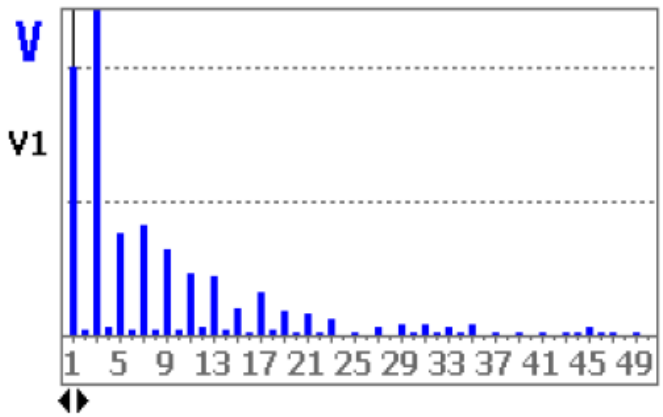

100

$\%$

50

(f)

Fig.4 .Hardware results of Voltage waveform at firing angle of $90^{\circ}$ :(a) $25 \mathrm{~Hz}$ frequency (b)16.66 $\mathrm{Hz}$ frequency (c)12.5Hz frequency (d) $8.33 \mathrm{~Hz}$ frequency (e) $10 \mathrm{~Hz}$ frequency (f)Harmonic spectrum at $10 \mathrm{~Hz}$ frequency

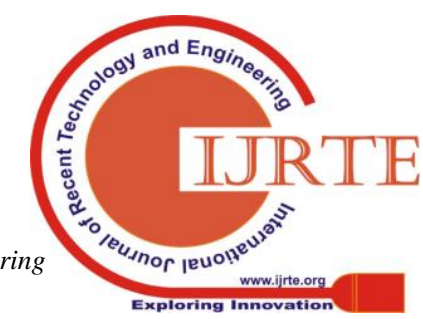




\section{HARDWARE RESULTS}

The experimental prototype is tested by varying firing angle and frequency. The Hardware results of Voltage waveform andHarmonic Spectrum measured using fluke power logger is presented in fig 3(a) forinput at $50 \mathrm{~Hz}$ frequency fig. 3(b) - 3(c) foroutput frequency of $16.66 \mathrm{~Hz}$ and $8.33 \mathrm{~Hz}$. The output waveform for firing angle of $90^{\circ}$ for variousfrequencies arepresentedfig. 4(a) -fig 4(f). The THD is $98.9 \%$ at frequency $10 \mathrm{~Hz}$ at firing angle of $90^{\circ}$ as shown in fig 4(e). It is revealedthat with rise in firing angle the THD has increased drastically.

\section{CONCLUSION}

The simulation and experimental studies are presented for a Direct $\mathrm{AC}-\mathrm{AC}$ converter. The harmonic spectrum of direct $\mathrm{AC}-\mathrm{AC}$ cyclo-converter is analyzed at various frequencies and firing angle. It is observed that THD significantly increases with increase in firing angle. Also, with reduction in frequency there is gradual increase in THD. It is suggested that matrix converter employing bidirectional switches with IGBT based PWM gate drive control, space vector modulation schemes can be further exploited for achieving reduction in harmonics.

\section{REFERENCES}

1. Rodríguez, J. R., Pontt, J., Newman, P., Musalem, R., Miranda, H., Moran, L., \& Alzamora, G. (2005). Technical evaluation and practical experience of high-power grinding mill drives in mining applications. IEEE transactions on industry applications, 41(3), 866-874.

2. Wu, B., Pontt, J., Rodríguez, J., Bernet, S., \& Kouro, S. (2008). Current-source converter and cycloconverter topologies for industrial medium-voltage drives. IEEE transactions on industrial electronics, 55(7), 2786-2797.

3. Rodríguez, J., Morán, L., Pontt, J., Espinoza, J., Díaz, R., \& Silva, E. (2004). Operating experience of shovel drives for mining applications. IEEE Transactions on Industry Applications, 40(2), 664-671.

4. Nagaraj, B., and R. Murugananth. "Optimum PID controller tuning using soft computing methodologies for industrial process." J Comput Sci India 4, no. 5 (2010): 1761-1768.

5. Morán, L., Albistur, C. A., \& Burgos, R. (2016). Multimega VAR passive filters for mining applications: Practical limitations and technical considerations. IEEE Transactions on Industry Applications, 52(6), 5310-5317.

6. Symonds, A., \& Laylabadi, M. (2013, October). Large cycloconverter drives in mining applications. In 2013 IEEE Industry Applications Society Annual Meeting (pp. 1-12). IEEE.

7. Liu, Y., Heydt, G. T., \& Chu, R. F. (2005). The power quality impact of cycloconverter control strategies. IEEE Transactions on power delivery, 20(2), 1711-1718.

8. Ahmed, W., Ali, N., Nazir, S., \& Khan, A. (2019). Power Quality Improving Based Harmonical Studies of a Single Phase Step Down Bridge-Cycloconverter. J. Electrical Systems, 15(1), 109-122.

9. M. Vsquez, J. Pontt, and V. Arredondo, "Cycloconverter interharmonics current analysis under unbalanced load based on a real-time simulation," in Int. Conf. on Ind. Technol., Seville, Mar.17-19 2015, pp. 683-689

10. J. San Martin, J. Pontt, F. Bello, and R. Aguilera, "Interharmonics power losses estimation in power transformer fed high power cycloconverter drive," in Industry Applications Society Annual Meeting, 2008. IAS'08. IEEE, pp. 1-5, IEEE, 2008.
11. Kavitha, R., \& Thottungal, R. (2018). Reconfigurable Selective Harmonic Elimination Technique for Wide Range Operations in Asymmetric Cascaded Multilevel Inverter. Journal of Power Electronics, 18(4), 1037-1050.

12. P. Syam, G. Bandyopadhyay, P. K. Nandi, and A. K. Chattopadhyay, "Simulation and experimental study of interharmonic performance of a cycloconverterfedsynchronous motor drive," Energy Conversion, IEEE Transactions on, vol. 19, no. 2, pp. 325-332, 2004.

13. Antunes, H. M., Pires, I. A., \& Silva, S. M. (2018, September). Evaluation of Series and Parallel Hybrid Filters Applied to Hot Strip Mills with Cycloconverters. In 2018 IEEE Industry Applications Society Annual Meeting (IAS) (pp. 1-6). IEEE.

14. Premalatha, K. (2015). Harmonic Current Compensation in Self Excited Induction Generator using Active Filter. Istanbul University-Journal of Electrical \& Electronics Engineering, 15(1), 1873-1881

15. Bessadet, I., \& Tedjini, H. (2018, December). The Performances of Hybrid Filter in Elimination of AC-AC Converters Harmonics Pollution. In 2018 6th International Renewable and Sustainable Energy Conference (IRSEC) (pp. 1-6). IEEE. 